\title{
$\forall$ \\ IJCRR \\ Isolation and Characterization of Bioactive Compounds from M. Stenopetala Root Extracts for Medicinal Values
}

Section: Healthcare

ISI Impact Factor

(2019-20): 1.628

IC Value (2019): 90.81

$\operatorname{SJIF}(2020)=7.893$

(c) (i) (8)

Copyright@IJCRR

\author{
Asnake Haile Alemu ${ }^{1}$, Kusse Gudishe Goroya ${ }^{1, *}$, Filippo Tamiru Tulu² \\ 'Department of Physics, College of Natural and Computational Sciences, Wolaita Sodo University, P. O. Box 138, Wolaita, Ethiopia; \\ ${ }^{2}$ Department of Chemistry, College of Natural and Computational Sciences, Hawassa University, Hawassa, P. O. Box 05, Ethiopia.
}

\section{ABSTRACT}

Introduction: The worldwide investigation of plant species for the treatment of various diseases and infections is still valuable. In developing countries, such as Ethiopia, where health care coverage is less, traditional medicine has played a significant role in treating health problems. Moringa stenopetala is among plant species widely used in traditional medicine for treatments of human health cases.

Aims: This study was conducted to isolate bioactive compounds from Moringa stenopetala root for medicinal purposes.

Methodology: The dried root of Moringa stenopetala was extracted with different solvents: n-hexane, dichloromethane/methanol (1:1) and methanol using maceration.

Results: Phytochemical analysis confirmed the presence of alkaloids, saponins, flavonoids, phenols, steroids, glycosides, terpenoids and tannins. Compounds were isolated and the compounds were characterized using results from spectroscopic techniques (IR, 1H-NMR, 13C-NMR and DEPT-135). The results signify that isolated and characterized compounds are (5E, 7Z, 10E)- 4,5,6,7-tetramethylnonadeca-5,7,10-trienoic acid and (4E,6E,8E)-pentadeca-4,6,8-trienoic acid with a structure that nearly look like simple fatty acids.

Conclusion: Fatty acids are known to possess antimicrobial activities of different strains and the result of this work supports the indigenous knowledge of the community of using this tree for antimalarial and anti-pain treatments.

Key Words: Crude extract, Characterization, M. Stenopetala, NMR, IR, Isolation

\section{INTRODUCTION}

Medicinal plants are a rich source of compounds that can be used to develop drug synthesis. Parts or the whole plant of medicinal plants that may be used for medical purposes. The active compounds in most parts of the medicinal plants have direct or indirect therapeutic effects and are used as medicinal agents. ${ }^{1}$ Africa is a rich source of medicinal plants. About 800 species of the medicinal plants grown in Ethiopia are used for treating different medical conditions and, hence, Ethiopia is considered as the home of some of the most diverse plant species in Africa. ${ }^{2}$

Moringa belongs to the flowering plant family Moringaceae. It comprises about 13 species that range from tiny herbs to massive trees in size. ${ }^{3}$ The most widely known species is Moringa oleifera, a multipurpose tree native to
India and cultivated throughout the tropics. An overview study of Alessandro et al. ${ }^{4}$ saw the cultivation, genetic, ethnopharmacology, phytochemistry and pharmacology of Moringa oleifera from itsleaves constituents. M. stenopetala, an African species, is also widely grown, but to a much lesser extent than M. oleifera. M. stenopetala is an important indigenous vegetable in southwestern Ethiopia where it is cultivated as a food crop ${ }^{5}$ in southern parts of Ethiopia like Konso and Darashe. ${ }^{6}$ The fresh leaves of the plant are cooked and consumed by the local communities. Its root parts are often used to treat malaria and other health problems. Various reports also show the antileishmanial, antitrypanosomal, antifertility, and antidiabetic activities of M. stenopetala. People with high blood pressure boil the leaves and drink the water to get relief from their aliment. ${ }^{6,7}$

Corresponding Author:

Kusse Gudishe Goroya, Department of Physics, College of Natural and Computational Sciences, Wolaita Sodo University, P. O. Box 138, Wolaita, Ethiopia; Ph: +251993900417; Email: anaxorma@gmail.com

ISSN: 2231-2196 (Print)

Received: 28.03 .202
ISSN: 0975-5241 (Online)

Revised: 21.05 .2021
Accepted: 03.06.2021
Published: 01.12 .2021 
For the investigation of constituents of the traditional medicinal plants, several researchers reported biological activities of crude extracts from different parts of Moringa species as well as isolation of pure compounds. Of the common bioactive compounds alkaloids, flavonoids, phenols, glycosides are capable of inhibiting the growth of various kinds of bacteria, ${ }^{8}$ terpenoids show significant anti-viral, anti-bacterial, ${ }^{9}$ anti-malarial, anti-inflammatory, inhibition of cholesterol synthesis and anti-cancer activities, ${ }^{8}$ tannins known for their anti-tumour activities, ${ }^{10}$ saponins and steroids are effective in anti-inflammatory actions. ${ }^{11}$ Gopinathet et al. ${ }^{12}$ conducted research in India for isolation and identification of therapeutic compounds from Moringa oleifera and its antimicrobial activity. Isolation, characterization and derivatization of some bioactive components in Moringa oleifera leaves are identified by a study conducted in Nigeria. ${ }^{13}$

According to a study conducted in Arba Minch, Ethiopia, isolation of compounds from acetone extract of the root of Moringa stenopetala and evaluation of their antibacterial activities were done. ${ }^{14}$ Irrespective of some previous works on the phytochemical investigation from Moringa stenopetala, more intensive advanced scientific output awaits to know the constituents of this species with regards to the indigenous knowledge of the society. Thus, in this research phytochemical investigation was carried out to identify secondary metabolites and isolation of compounds from the root part of this plant.

\section{MATERIALS AND METHODS}

\section{Chemicals}

Reagents of n-hexane, dichloromethane and methanol were used for gradient extraction. Additionally, ethyl acetate and n-hexane for column elution, pre-coated thin-layer chromatography (TLC) (silica gel, Uv 254) were used for chromatographic analyses. To identify phytochemicals, reagents like Dragendroff's test reagents, dilute sodium hydroxide, ferric chloride, conc. Hydrochloric acid, concentrated sulphuric acid and chloroform were used.

\section{Materials}

Rotary evaporator (Heidolph, UK) for the concentration of crude extracts, Grant (Gl S400) thermostatic bath shaker for maceration of plant materials were used. Oven (model: N50L, GENLAB, WIDNES, England) for heating, analytical balance (AFP-110L) for weight measuring, UV chamber (Uvitec) for visualizing molecular segregation were used. 1H-NMR, 13C-NMR and DEPT-135 spectra were recorded using Bruker (400 MHz) spectrometer while IR spectra were obtained from Perkin Elmer BX infrared spectrometer (400$\left.4000 \mathrm{~cm}^{-1}\right)$.

\section{Plant Materials}

The root of Moringa stenopetala was collected in April 2019 from Konso Zone, Southern Ethiopia, and identified by Botanist at the Department of Biology, Hawassa College of Teacher Education where a voucher number (MS/0031) was given and the plant material was deposited. Then it was cut into small pieces and air-dried in the laboratory at room temperature for a month without exposure to sunlight. It was then milled to a suitable size for extraction using locally available mortar. A total of $1050 \mathrm{~g}$ plant powder was prepared for the further extraction procedure.

\section{Extraction}

One thousand and fifty grams of powdered Moringa stenopetala root was macerated by successive use of n-hexane, dichloromethane/ methanol (50\%:50\%) and methanol for 72 $\mathrm{h}$ with continuous shaking using a shaker machine one after another. Figure 4 indicates the general extraction techniques followed in this work. The resulting supernatant solution was filtered using Whatman filter paper No. 1. Residual solvent in each gradient extract was removed using Rota Vapor (Heidolph, UK) under reduced pressure. It was then dried in an oven at a temperature of $40^{\circ} \mathrm{C}$ to remove the solvent (dichloromethane/Methanol (1:1)) and kept in the refrigerator. The per cent yields of the extracts were calculated using
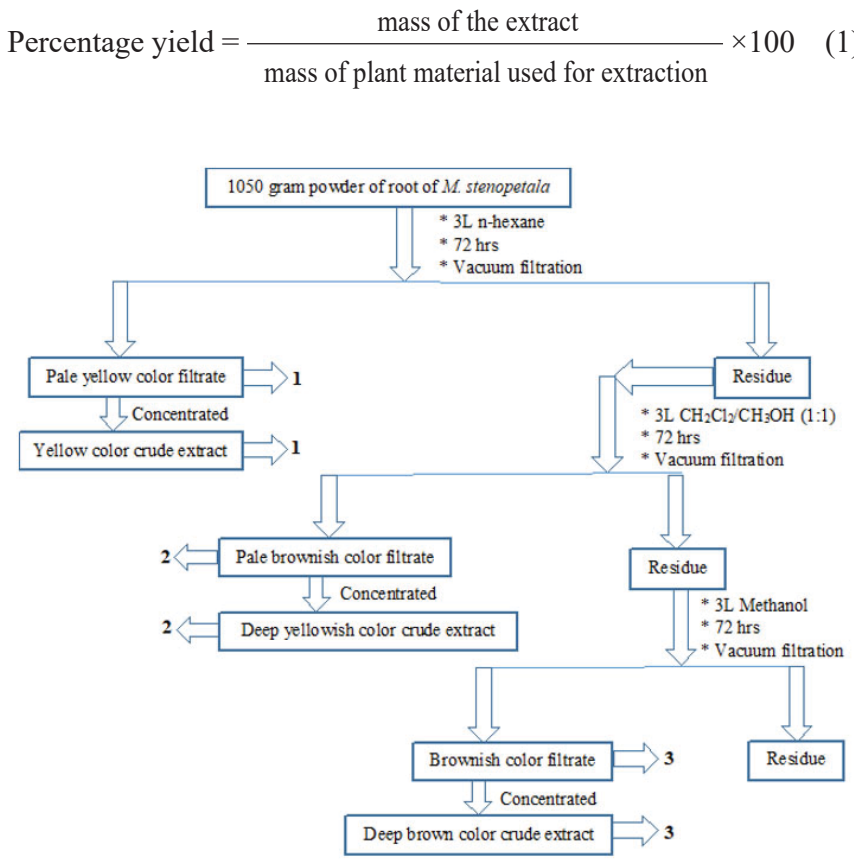

Schematic flow chart of extraction techniques used in this work.

\section{Phytochemical Screening Tests}

Phytochemical examinations were carried out for all the extracts as per the standard method reported in the literature. ${ }^{15}$, ${ }^{16}$ Based on these methods, identification tests for the presence of secondary metabolites namely: steroids (Liebermann 
Buchard reaction), terpenoids (Salkowski test), saponins (Froth test and Foam test), flavonoids (Alkaline reagent test and Lead acetate test), tannins, alkaloids (Mayer's test, Wagner's test, Dragendroff's test and Hager's test), phenols (Ferric chloride test) and glycosides (Keller-Killani test) were carried out.

\section{Isolation and Characterization of Compounds}

Among the crude extracts carried out in this experiment, the crude extract of dichloromethane/ methanol showed the best TLC profile. Then, $5.2 \mathrm{~g}$ of dichloromethane/methanol extract was adsorbed onto silica gel (12 g) and subjected to column chromatographic isolation. The column $(1.5 \mathrm{~m}$ length and $1.5 \mathrm{~cm}$ diameter) was then eluted using ethyl acetate and $n$-hexane mixture starting from $100 \% \mathrm{n}$-hexane (3 L) and gradually increasing polarity by adding ethyl acetate. The TLC analysis of crude extract in various combinations of solvent varying polarity was used to select the solvent system for the isolation of pure compounds. In doing so, ethyl acetate and n-hexane combinations were able to show the separation of pigments on TLC of the dichloromethane/methanol crude extracts. Hence, the mixture of ethyl acetate and n-hexane has been used in different combinations with a slight increase in non-polarity.

The collected fraction was concentrated using a Rotary evaporator. Fractions were tested using TLC. The spots on the TLC plates were visualized using UV light (at 254 $\mathrm{nm}$ and $365 \mathrm{~nm}$ ) followed by iodine vapour. Pure isolates were produced in (n-hexane/ethyl acetate) fractions (\%:\%): $85: 15$ and 80:20 in a combination of n-hexane and ethyl acetate, respectively. The column chromatographic separation led to the isolation of two pure compounds. The structural elucidations of these compounds were carried out based on data obtained from spectroscopic techniques (IR and NMR).

\section{RESULTS AND DISCUSSIONS}

\section{Mass of Crude Extracts}

Depending on the method indicated materials and methods, crude extracts were carried out and allowed to dry completely. The percentage yield of successive extracts of the root of M. stenopetala was determined. As presented in Table 1, the gradient extraction of the roots of the targeted plant using three different solvents systems produce different yields. The percentage of crude extract of methanol was found to be higher than the other crude extracts, due to the ranges of polarity. However, was dichloromethane/methanol (1:1) solvent was selected for further extraction as it showed an excellent TLC profile.

Table 1: The percentage yield of each gradient extract

\begin{tabular}{lcc}
$\begin{array}{l}\text { The solvent system used for } \\
\text { extraction }\end{array}$ & $\begin{array}{c}\text { Mass of Crude } \\
\text { extract }(\mathrm{g})\end{array}$ & Yield (\%) \\
n-hexane & 1.8 & 0.17 \\
Dichloromethane/Methanol (1:1) & 5.2 & 0.495 \\
Methanol & 40 & 3.81 \\
\hline
\end{tabular}

\section{Phytochemical Screening Tests}

Preliminary Phytochemical screening tests were performed on eight types of bioactive compounds. As can be seen from Table 2, n-hexane, methanol and dichloromethane/methanol $(1: 1)$ crude extracts showed the presence of alkaloids, flavonoids, phenols, glycosides, terpenoids, tannins, saponins and steroids except tannins is absent in crude extract of methanol.

Table 2: Phytochemical analysis of $M$. stenopetala crude extracts

\begin{tabular}{|c|c|c|c|c|c|c|c|}
\hline \multirow{3}{*}{$\begin{array}{l}\text { Bioactive } \\
\text { component }\end{array}$} & \multirow[t]{3}{*}{ Reagents used } & \multicolumn{6}{|c|}{ The solvent used for crude extraction } \\
\hline & & \multicolumn{2}{|c|}{ n-hexane } & \multicolumn{2}{|c|}{ Dichloromethane/methanol } & \multicolumn{2}{|c|}{ Methanol } \\
\hline & & Result & Observed Colour & Result & Observed colour & Result & Observed colour \\
\hline Alkaloids & Dragendroff's reagent & ++ & Red colour & ++ & Red colour & ++ & Red colour \\
\hline Flavanoids & Alkaline reagent & ++ & Deep yellow colour & ++ & $\begin{array}{c}\text { Deep } \\
\text { yellow colour }\end{array}$ & ++ & Deep yellow colour \\
\hline Phenols & Ferric chloride & ++ & Bluish black colour & ++ & Bluish black colour & ++ & Bluish black colour \\
\hline Glycosides & Keller-Killani test & ++ & Light reddish-brown & ++ & Light reddish-brown & ++ & Light reddish-brown \\
\hline Terpenoids & Salkowski test & ++ & Radish brown colour & ++ & Radish brown colour & ++ & Radish brown colour \\
\hline Tannins & Ferric chloride & ++ & Brownish green & ++ & Brownish green & -- & -- \\
\hline Saponins & Distilled water & ++ & $\begin{array}{l}\text { Strong foam forma- } \\
\text { tion }\end{array}$ & ++ & $\begin{array}{l}\text { Strong } \\
\text { foam formation }\end{array}$ & ++ & $\begin{array}{l}\text { Strong foam forma- } \\
\text { tion }\end{array}$ \\
\hline Steroids & $\begin{array}{l}\text { Liebermann Buchard } \\
\text { reaction }\end{array}$ & ++ & Light blue-green & ++ & Light blue-green & ++ & Light blue-green \\
\hline
\end{tabular}

Key: Strong (++) Absent (--) 


\section{Structural Elucidation of Compound 1}

Compound 1, MS1, was obtained as a white crystal appearance $(38.6 \mathrm{mg})$. It was isolated from a combined $15 \%$ of ethyl acetate in n-hexane for elution of the chromatography. The absence of doublet band at/near 2850 and 2750 $\mathrm{cm}^{-1}$ in the IR (400-4000 $\left.\mathrm{cm}^{-1}\right)$ spectrum (Appendix A - Fig A1) indicate that the compound has no aldehyde functional group. The absence of a strong band in the rage or around $1700-1800 \mathrm{~cm}^{-1}$ shows that the compound has no carbonyl functional group. The absence of weak bands in the range of 2000 and $1650 \mathrm{~cm}^{-1}$ indicates that the compound has no aromatic functional group. On the other hand, the observed stretching broadband at $3430 \mathrm{~cm}^{-1}$ indicates the presence of the carboxylic acid functional group. The strong band around $2900 \mathrm{~cm}^{-1}$ represents the $\mathrm{C}-\mathrm{H}$ stretch of alkenes whereas the bands around $2854.45 \mathrm{~cm}^{-1}$ indicate the $\mathrm{C}-\mathrm{H}$ stretching of methyl groups. The observed data suggest that compound MS1 could be a carboxylic acid possessing a $\mathrm{C}=\mathrm{C}$ double bond in its chain.

In the ${ }^{1} \mathrm{H}-\mathrm{NMR}(400 \mathrm{MHz}, \mathrm{DEMSO})$ spectrum of compound MS1 (Appendix A - Fig A2), the peaks at $\delta 0.7$ and 0.9 indicate the presence of protons of two methyls $\left(-\mathrm{CH}_{3}\right)$ groups whereas the peak at $\delta 5.26,5.40$ and 5.49 indicate the presence of aliphatic protons in compound MS1. These ${ }^{1} \mathrm{H}-\mathrm{NMR}$ data along with the observed IR spectral suggests that compound MS1 be most likely fatty acid. The ${ }^{13} \mathrm{C}-\mathrm{NMR}$ (400MHz) spectrum of compound MS1 shows signals at $128.01,128.20,128.35,130.17,130.34$ and $131.94 \mathrm{ppm}$ which are assigned to C-5, C-7 and C-10 double bonds, respectively. ${ }^{13} \mathrm{C}-\mathrm{NMR}$ (Appendix A- FigA3) and DEPT-135 (Appendix A - Fig A4) spectra show 25.67 and $29.45 \mathrm{ppm}$ signals, respectively, that can be assigned to five methyls, ten methylene, four methine and four quaternary carbon atoms (Table 4). Similar to that IR data, observed NMR data of compound MS1 were also found to be consistent with the reported data of Mulugeta et al. ${ }^{13}$ These indicate that the compound has a similar chemical structure with a simple fatty acid structure (Figure 1).

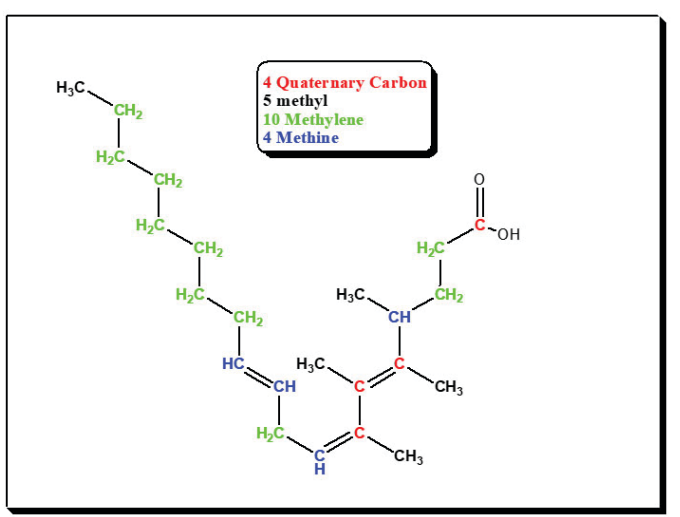

(5E,7Z,10E)-4,5,6,7-tetramethylnonadeca-5,7,10-trienoic acid Figure 1: Structural elucidation of compound MS1.
Mulugeta et al. ${ }^{14}$ reported a compound with the structure of the fully simple aliphatic compound and quite similar with MS1 though it has a single double bond on carbon number 9-10. Compound MS1 has three double bonds on carbon numbers 5, 7 and 10, due to this compound MS1 shows some spectral differences. Since MS1 is a polyunsaturated fatty acid, it has more electron cloud density than that of the reported one because of this fact the compound is more reactive. In addition to this, MS1 has more benefit in free radical scavenging ability as result it has a great preventing effect.

Table 3: ${ }^{13}$ C-NMR (in ppm) and DEPT-135 (in ppm) data of compound MS1 along with corresponding reported data of oleic acid.

\begin{tabular}{|c|c|c|c|c|c|}
\hline $\begin{array}{l}\text { Carbon } \\
\text { atom }\end{array}$ & $\begin{array}{c}{ }^{13} \text { C-NMR } \\
\text { data } \\
\text { MS1 }\end{array}$ & $\begin{array}{c}{ }^{13} \text { C-NMR } \\
\text { data of } \\
\text { Oleic } \\
\text { acid }[7]\end{array}$ & $\begin{array}{c}\text { DEPT-135 } \\
\text { data of } \\
\text { MS1 }\end{array}$ & $\begin{array}{c}\text { DEPT- } \\
\text { 135 data } \\
\text { Oleic } \\
\text { acid }[7]\end{array}$ & $\begin{array}{l}\text { Nature of } \\
\text { carbon }\end{array}$ \\
\hline$C-1$ & 174.93 & 180.196 & - & - & $\mathrm{C}$ \\
\hline$C-2$ & 34.15 & 34.078 & 31.75 & 34.078 & $\mathrm{CH}_{2}$ \\
\hline$C-3$ & 29.46 & 24.683 & 31.41 & 24.683 & $\mathrm{CH}_{2}$ \\
\hline$C-4$ & 31.36 & 29.153 & 31.36 & 29.155 & $\mathrm{CH}_{2}$ \\
\hline$C-5$ & 137.0 & 29.073 & - & 29.073 & $C$ \\
\hline C-6 & 128.01 & 29.447 & - & 29.447 & $C$ \\
\hline$C-7$ & 131.94 & 29.606 & - & 29.684 & $C$ \\
\hline$C-8$ & 130.17 & 27.162 & 130.34 & 27.161 & $\mathrm{CH}$ \\
\hline$C-9$ & 31.76 & 129.734 & 31.36 & 129.737 & $\mathrm{CH}$ \\
\hline C-10 & 128.01 & 130.030 & 130.17 & 130.031 & $\mathrm{CH}_{2}$ \\
\hline$C-11$ & 128.35 & 27.227 & 128.21 & 27.226 & $\mathrm{CH}$ \\
\hline$C-12$ & 29.46 & 29.706 & 29.46 & 29.776 & $\mathrm{CH}_{2}$ \\
\hline$C-13$ & 29.19 & $29 \cdot 338$ & 26.78 & $29 \cdot 337$ & $\mathrm{CH}_{2}$ \\
\hline$C-14$ & 29.01 & 29.536 & 22.52 & 29.535 & $\mathrm{CH}_{2}$ \\
\hline$C-15$ & 29.07 & 29.256 & 14.39 & 29.256 & $\mathrm{CH}_{3}$ \\
\hline$C-16$ & 27.07 & 31.941 & 27.07 & 31.941 & $\mathrm{CH}_{2}$ \\
\hline$C-17$ & 25.67 & 22.707 & 25.67 & 22.706 & $\mathrm{CH}_{2}$ \\
\hline$C-18$ & 22.56 & 14.133 & 22.43 & 14.134 & $\mathrm{CH}_{2}$ \\
\hline C-19 & 22.43 & - & 24.96 & - & $\mathrm{CH}_{3}$ \\
\hline $\mathrm{C}-2 \mathrm{O}$ & 20.49 & - & 40.23 & - & $\mathrm{CH}_{3}$ \\
\hline$C-21$ & 14.37 & - & $14 \cdot 37$ & - & $\mathrm{CH}_{3}$ \\
\hline$C-22$ & 14.56 & - & 14.37 & - & $\mathrm{CH}_{3}$ \\
\hline $\mathrm{C}-23$ & 22.43 & - & 40.23 & - & $\mathrm{CH}_{3}$ \\
\hline
\end{tabular}

DEPT - distortionless enforcement by polarization transfer, NMR - nuclear magnetic resonance

\section{Structural Elucidation of Compound 2}

The second compound, Compound MS2, was obtained as a light yellowish crystal appearance $(24.46 \mathrm{mg})$. It was isolated from a combined $20 \%$ of ethyl acetate in n-hexane for elution of the chromatography. IR spectrum (Appendix B - Fig 
A5) for compound MS2 has no doublet band at/near 2850 and $2750 \mathrm{~cm}^{-1}$ that indicating that the compound has no aldehyde functional group. The presence of a strong band in the rage around $1700-1800 \mathrm{~cm}^{-1}$ also shows that the compound has a carbonyl functional group.

Table 4: ${ }^{13} \mathrm{C}-\mathrm{NMR}$ (in ppm) and DEPT-135 (in ppm) data of compound MS2 along with corresponding reported data of oleic acid.

\begin{tabular}{|c|c|c|c|c|c|}
\hline $\begin{array}{l}\text { Carbon } \\
\text { atom }\end{array}$ & $\begin{array}{c}{ }^{13} \text { C-NMR data of } \\
\text { MS2 }\end{array}$ & $\begin{array}{l}{ }^{13} \mathrm{C}-\mathrm{NMR} \text { data of } \\
\text { oleic acid }{ }^{13}\end{array}$ & $\begin{array}{c}\text { DEPT-135 data of } \\
\text { MS2 }\end{array}$ & $\begin{array}{l}\text { DEPT-135 data of } \\
\text { oleic acid }^{13}\end{array}$ & $\begin{array}{c}\text { Nature of car- } \\
\text { bon }\end{array}$ \\
\hline$C-1$ & 174.96 & 180.196 & - & - & C \\
\hline$C-2$ & 36.7 & 34.078 & 31.75 & 34.078 & $\mathrm{CH}_{2}$ \\
\hline$C-3$ & 30.6 & 24.683 & 31.41 & 24.683 & $\mathrm{CH}_{2}$ \\
\hline$C-4$ & 132.4 & 29.153 & 132.97 & 29.155 & $\mathrm{CH}$ \\
\hline$C-5$ & 129.5 & 29.073 & 128.65 & 29.073 & $\mathrm{CH}$ \\
\hline C-6 & 130.4 & 29.447 & 129.71 & 29.447 & $\mathrm{CH}$ \\
\hline$C-7$ & 130.4 & 29.606 & 128.98 & 29.684 & $\mathrm{CH}$ \\
\hline C-8 & 128.8 & 27.162 & 127.59 & 27.161 & $\mathrm{CH}$ \\
\hline$C-9$ & 135.7 & 129.734 & 133.25 & 129.737 & $\mathrm{CH}$ \\
\hline C-10 & 33.8 & 130.030 & 40.17 & 130.031 & $\mathrm{CH}_{2}$ \\
\hline$C-11$ & 30.1 & 27.227 & 40.38 & 27.226 & $\mathrm{CH}_{2}$ \\
\hline C-12 & 29.5 & 29.706 & 29.46 & $29 \cdot 776$ & $\mathrm{CH}_{2}$ \\
\hline$C-13$ & 32.0 & $29 \cdot 338$ & 26.78 & 29.337 & $\mathrm{CH}_{2}$ \\
\hline C-14 & 22.8 & 29.536 & 22.52 & 29.535 & $\mathrm{CH}_{2}$ \\
\hline C-15 & 14.1 & 29.256 & 14.39 & 29.256 & $\mathrm{CH}_{3}$ \\
\hline
\end{tabular}

The absence of weak bands in the range of 2000 and 1650 $\mathrm{cm}^{-1}$ indicates that the compound has no aromatic functional group. On the other hand, the observed stretching broadband at $3402.20 \mathrm{~cm}^{-1}$ indicates the presence of the carboxylic acid functional group. The strong band around $2923 \mathrm{~cm}^{-1}$ represents the $\mathrm{C}-\mathrm{H}$ stretch of alkenes whereas the bands around $2854.45 \mathrm{~cm}^{-1}$ indicates the $\mathrm{C}-\mathrm{H}$ stretching of methyl groups. The observed data suggest that compound MS2 could be a carboxylic acid possessing a $\mathrm{C}=\mathrm{C}$ double bond in its chain.

In the ${ }^{1} \mathrm{H}-\mathrm{NMR}(400 \mathrm{MHz}, \mathrm{DEMSO})$ spectrum of compound MS2 (Appendix Fig A6), the peaks at $\delta 0.8$ indicate the presence of protons of one methyl $\left(-\mathrm{CH}_{3}\right)$ groups whereas the peak at $\delta 7.351,7.629$ and 7.809 indicate the presence of unsaturated methine protons in compound MS2. These ${ }^{1} \mathrm{H}-$ NMR data along with the observed IR spectral suggest that compound MS2 to be most likely fatty acid with fifteen carbon numbers. The ${ }^{13} \mathrm{C}-\mathrm{NMR}$ spectrum of compound MS2 shows signals at $128.65,128.98,129.71,131.29$, and 133.25 ppm which are assigned to C-4, C-6 and C-8 have double bonds, respectively. ${ }^{13} \mathrm{C}-\mathrm{NMR}$ (Appendix B - Fig A7) and DEPT-135spectra (Appendix B- Fig A8) show that compound MS2 has seven methylene, one methyl, six methines and one quaternary carbon (Table 5). Both IR and NMR data of compound MS2 were also found to be consistent with the reported data of Mulugeta et al. ${ }^{14}$ These indicate the compound has a similar chemical structure with a simple fatty acid structure (Figure 2).

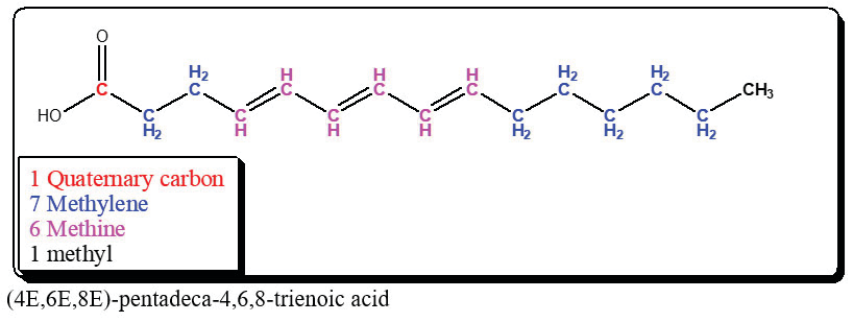

Figure 2: Structural elucidation of compound MS2.

Previous work of Mulugeta et al. ${ }^{14}$ a compound with a structure fully simple aliphatic compound and quite similar with MS2 elucidated in this work though it has a single double bond on carbon number 9-10. Compound MS2 in the present work has three double bonds on carbon numbers 4, 6 and 8 and it shows some spectral difference. Since MS2 is a polyunsaturated fatty acid, it has more electron cloud density than that of the reported one because of this fact the compound is more reactive. In addition to this MS2 has a more benefit free radical scavenging ability effect. 


\section{CONCLUSION}

Phytochemical screening of the root of $M$. stenopetala Ethiopian flora confirmed the presence of alkaloids, saponins, flavonoids, phenols, steroids, glycosides, terpenoids and tannins. Chromatographic separation dichloromethane/ methanol (1:1) yielded three compounds. The two fatty acidcontaining compounds $(5 \mathrm{E}, 7 \mathrm{Z}, 10 \mathrm{E})$ - 4,5,6,7-tetramethylnonadeca-5,7,10-trienoic acid and (4E,6E,8E)-pentadeca4,6,8-trienoic acid are fully elucidated. Fatty acids are known to possess antimicrobial activities of different strains and the result of this work supports the indigenous knowledge of the community of using this tree for antimalarial and anti-pain treatments.

Supplementary Materials: The IR, NMR spectra of compounds MS1 and MS2are included in the Supplementary Materials.

\section{ACKNOWLEDGEMENTS}

Authors acknowledge the immense help received from the scholars whose articles are cited and included in references of this manuscript. The authors are also grateful to authors/ editors/publishers of all those articles, journals and books from where the literature for this article has been reviewed and discussed.

Conflict of Interest: Authors have no conflict of interest to report.

Funding: No source of funding received.

Author Contributions: A.H.A.: collected plant material, carried out the experimental work. F.T.T. assisted in the extraction, isolation, preparation and identification of the compounds, including interpretation of spectral data. K.G.G.: administered all the research activities and corrected, edited the manuscript, proofread the manuscript before submission. All authors read and approved the final manuscript.

\section{REFERENCES}

1. Fatemeh J, Zahra L, Hossein AK. Medicinal plants: History and future perspective. J Herbmed Pharmacol. 2018;7:1-7.
2. Worku A. An Overview of Ethiopian Traditional Medicinal Plants Used for Cancer treatment. Eur J Med Plants. 2016;14:116.

3. Ojeaga I, Haruna HG, Tajudeen BL. Phytochemical and antimicrobial studies on Moringa Oleifera leaves extracts. IOSR J Environ Sci Toxicol Food Technol. 2014;8:39-45.

4. Alessandro L, Alberto S, Alberto B, Alberto S, Junior A. Simona, B. Cultivation, genetic, ethnopharmacology, phytochemistry and pharmacology of Moringa oleifera leaves: An Overview. Int J Mol Sci. 2015;16:12791-12835.

5. Eyassu S. Actual and potential applications of Moringa stenopetala, underutilized indigenous vegetable of Southern Ethiopia: A Review. Int J Agric Food Res. 2014;3:8-19.

6. Netsanet F, Hirut B, Asfaw M, Sileshi D, Biruktawit G, Bekesho G. Diuretic activity of the aqueous crude extract and hot tea infusion of Moringa stenopetala (Baker f.) Cufod. leaves in rats. J Exp Pharmacol. 2017;9:73-80.

7. Asaminew A, Denghua Y, Abel G, Xinshan S, Hao W. Wastewater treatment potential of Moringa stenopetala over Moringa olifera as a natural coagulant, antimicrobial agent and heavy metal removals.Cogent Environ Sci. 2018;4:1433507.

8. Nassar ZD, Aisha AF, Abdul Majid AM. The pharmacological properties of terpenoids from Sandoricum koetjape. Webmedcentral complement Med. 2010;1:WMC001311.

9. Mayee R, Thosar A. Evaluation of Antibacterial Activity of Moringa Oleifera against Some Bacterial Strains. Int J Curr Res Rev. 2011;3:69-74.

10. Okuda T, Ito H. Tannins of constant structure in medicinal and food plants -hydrolysable tannins and polyphenols related to tannins.Molecules. 2011;16:2191-2217.

11. Safiya S, Himanshu V, Nirmal Y, Mirinda J, Jyothi B. Applications of steroid in clinical practice: A Review. Int Sch Res Network ISRN Anesthesiol 2012;11.

12. Gopinath LR, Jeevitha S, Gokiladevi T, Archaya S. Isolation and identification of therapeutic compounds from Moringa oleifera and its antimicrobial activity. IOSR J Pharm Bio Sci. 2017;12:01-07.

13. Ogundele VA, Fadeyi OE. Isolation, characterization and derivatization of some bioactive components in Moringa Oleifera leaves. Nat Prod Chem Res. 2015;3:189.

14. Mulugeta T, Legesse A, Yinebeb T, Diribe M, Shiferaw D. Isolation of the compound from acetone extract of root wood of Moringa stenopetala and evaluation of their antibacterial activities. Res J Med Plants. 2013;7:32-47.

15. Ganesh S, Vennila JJ. Phytochemical Analysis of Acanthus ilicifolius and Avicennia officinalis by GC-MS. Res J Phytochem. 2011;5:60-5.

16. Prashant T, Bimlesh K, Mandeep K, Gurpreet K, Harleen K. Phytochemical screening and extraction: A Review. Int Pharm Sci. 2011;1:98-104. 